\title{
Psychosocial Support Improves Treatment Adherence Among MDR-TB Patients: Experience from East Kazakhstan
}

\author{
G. Kaliakbarova ${ }^{1}$, S. Pak ${ }^{1}$ N. Zhaksylykova ${ }^{2}$, G. Raimova ${ }^{2}$, B. Temerbekova ${ }^{3}$ and S. van den Hof ${ }^{*}, 4$ \\ ${ }^{1}$ KNCV Representative Office in Central Asia, Almaty, Kazakhstan \\ ${ }^{2}$ Regional tuberculosis dispensary of Semei city, East Kazakhstan oblast, Kazakhstan \\ ${ }^{3}$ Oblast tuberculosis dispensary of Oskemen city, East Kazakhstan oblast, Kazakhstan \\ ${ }^{4}$ KNCV Tuberculosis Foundation, The Hague, The Netherlands \\ ${ }^{5}$ Department of Global Health, Academic Medical Center, University of Amsterdam, Amsterdam Institute for Global \\ Health and Development, The Netherlands
}

\begin{abstract}
A novel patient-oriented treatment delivery program was introduced for multi-drug resistant tuberculosis (MDR-TB) patients at high risk of treatment default in East Kazakhstan region, The Republic of Kazakhstan. In parallel interventions were introduced to improve programmatic and clinical management for all MDR-TB patients. To assess the effects of the patient support program on patient default rates, we analyzed the characteristics of MDR-TB patients referred to the psychosocial support (PSS) program, treatment adherence before and during the intervention for patients referred to the patient support program.

In 2010, the total number of MDR-patients starting second-line drug MDR-TB treatment was 426. The PSS program supported $228(53 \%)$ patients considered to be at high risk of treatment default. The program contributed to strengthening of management of all MDR-TB patients during the ambulatory, continuation phase of treatment. The proportion of drug doses taken under direct observation improved from $48 \%$ to $97 \%$, while division of intake of second-line anti-TB drugs in 2-3 portions per day decreased from $20 \%$ in 2009 to $0 \%$. Interruptions of anti-TB drugs for at least one day decreased from $18 \%$ to $4 \%$ among all MDR-TB patients. Among patients included in the PSS program, no treatment default was observed and only one patient missed doses of treatment.

In conclusion, our patient-oriented support program was successful in reducing rates of treatment default among MDRTB patients.
\end{abstract}

Keywords: Kazakhstan, MDR-TB, patient support, PMDT, Treatment adherence, Treatment default, KNCV.

\section{INTRODUCTION}

The notification rate for new tuberculosis (TB) patients in Kazakhstan has been declining since 2002, from 165 per 100,000 population in 2002 to 87 per 100,000 in 2011. In this period, the notification of TB mortality decreased from 24 to 8 per 100,000. Multi-drug resistant (MDR) TB, defined as $\mathrm{TB}$ resistant to the two most important drugs, i.e. rifampicin and isoniazid, remains one of the key challenges for TB control in Kazakhstan. MDR-TB requires about two years of treatment with less effective, but more toxic drugs, often leading to side effects In 2011, 19\% of new TB patients and $53 \%$ of retreatment TB patients were infected with a MDR-TB strain.

East Kazakhstan oblast (EKO) is one of the biggest regions situated in the east of Kazakhstan. It is bordering Russia and China, and about $1200 \mathrm{~km}$ long from North to

*Address correspondence to this author at the KNCV Tuberculosis Foundation, P.O. Box 146, 2501 CC The Hague, The Netherlands;

Tel: +31 70 4270985; Fax: +31 70 3584004;

E-mail: vandenhofs@kncvtbc.nl
South and $800 \mathrm{~km}$ from East to West. The total population is 1418450 people (2010). The oblast contains 19 administrative territories (rayons). East Kazakhstan oblast has one of the highest prevalence of MDR-TB in the country: $36 \%$ among new patients, $53 \%$ among retreatment patients, and over $85 \%$ among chronic patients. Inappropriate implementation of the international directly observed therapy-short course (DOTS) strategy led to an increase of MDR-TB in EKO. In addition, late diagnosis of DR-TB and lack of infection control contributed to transmission of resistant strains [1].

As has been observed in other former Soviet Union settings, most of MDR-TB patients in EKO come from vulnerable groups: the poor, homeless, ex-prisoners, people with HIV, drug or alcohol abusers, and migrants. These groups have limited access to TB services, which leads to late detection and continuing transmission. Also they are at increased risk of interrupting or defaulting treatment [2-4]. These patients join the pool of chronic TB patients and remain a source for TB transmission. After previous unsuccessful treatment regimens, these patients may have no confidence that another treatment regimen will cure them. 
Also because of hospitalization for about six months, painful injections, and symptoms of the disease and side effects, patients may become depressed $[5,6]$.

Psycho-social support may help patients to endure the long and unpleasant treatment, hereby improve treatment adherence and therefore treatment outcomes, and subsequently the epidemiological (MDR) TB situation [2, 3]. In EKO, very limited local budgets were available for social support for TB patients, and no psychological support was provided anywhere in the country.

\section{Technical Assistance}

KNCV Tuberculosis Foundation (KNCV) in the framework of the United States Agency for International Development (USAID), supported financially through the TB Control Assistance Program (TB CAP) has sought to improve support of MDR-TB cases in East Kazakhstan. Together with the oblast's health, social and prison system organizations, the project team from $\mathrm{KNCV}$ worked on improvement of programmatic management of drug-resistant TB (PMDT) and developed a model for psycho-social support of (MDR)TB patients. Here we describe how this patient support program was set up, and report on the evaluation of its pilot in 2010, including on the effects of this support on treatment adherence.

\section{METHODS}

\section{Political Commitment}

With regard to patient support, the project team established a working group on TB patient support under the EKO government (Akimat), and facilitated development of a model on psycho-social support for TB patients. The Working Group is chaired by the deputy chair (deputy Akim) of EKO and furthermore consists of representatives of the oblast health care department, TB services, social security department, and prison system. As prisoners with TB can be released during treatment, it is important that after discharge they transfer to the civil system so they continue treatment there. In order to increase political commitment at the oblast level the project team organized several meetings at oblast level; with representatives from the Akimat itself, the social security department, the labor and social security department of the Ministry of Labor and Social Affairs (MoLSA), and the oblast healthcare department and the local branch of the National Society of Red Crescent. The project team assisted the oblast Akimat in development of a budget for social support that was submitted to the local parliament for allocation of state funds. As a result, the model on psycho-social support was approved by the local government.

\section{Psycho-Social Support Groups}

A psycho-social support group (PSSG) was established in each of the two largest cities of the oblast - Oskemen and Semey. The teams consisted of psychologists, social workers and TB nurses, and were supervised by the heads of the ambulatory departments of TB dispensaries. The psychosocial support model was based on the oblast's situation, available resources, and experiences learnt from other MDRTB treatment sites in the Central Asian region. The model was implemented in EKO under supervision and coordination of the working group. The project team organized a study visit to Tomsk, Russia, for members of the working group and the PSSGs to learn from their experiences in TB patient support provision. Members of the PSSGs were trained in interpersonal communication during basic and refresher rounds of workshops. Documents related to provision of service to MDR-TB patients were developed and introduced: job descriptions, division of responsibilities among state bodies, reporting flow, monitoring and evaluation.

The psychologists in the PSSGs evaluated the psychological profile of patients, using a questionnaire which was initially developed by Medecins Sans Frontieres Holland for Karakalpakstan but was adjusted for EKO. Social workers evaluated the social profile of patients. Then the team discussed the results of these evaluations, and developed treatment retention plans for each patient based on their individual situations. It should be noted that during the first few months of implementation, the MDR-TB patients refused meetings with psychologists not recognizing that they really need psychological support. Step by step the psychologists earned patients' trust and had meetings with them and their supporters. Main psychological problems were related to uncertainty of treatment success, stigmatization, lack of support and understanding within their environment, fear to lose current relations, and not being able to get married in the future.

In Kazakhstan, patients are hospitalized during the intensive phase of treatment and usually treated on an outpatient basis during the continuation phase. For MDR-TB patients, the duration of the intensive phase is 6-9 months, the continuation phase about 12 months. As the risk of treatment interruption is biggest during outpatient treatment, the PSS program mainly focused on MDR-TB patients at the continuation phase of treatment. However, during the pilot introduction some patients deemed to be at risk for default during the intensive phase were also enrolled.

In terms of improvement of PMDT, the project team jointly with NTP and local partners has developed clinical protocols on all aspects of PMDT, and conducted trainings for health care staff from TB dispensaries and from primary health care centers where directly observed therapy (DOT) was initiated.

Technical assistance on general PMDT and specifically on psycho-social support was provided during regular supervision visits of senior consultants, project team and NTP specialists.

\section{Evaluation of Psychosocial Support}

During introduction and implementation of the pilot of the PSS program model in 2010 we conducted two rounds of interviews with different MDR-TB patients to assess their attitude towards the psycho-social support provided, and their understanding of the importance of uninterrupted treatment. Informed consent was obtained for all interviews, and interviews were anonymous. The PSSG under supervision of the project team designed a database for the collection of relevant information regarding the psychosocial profiles of MDR-TB patients, the support provided, and on treatment adherence (as noted on the medical cards). 


\section{RESULTS}

\section{Political Commitment}

Regular meetings with local authorities were held to report on the progress of the PSS model implementation, discussion of problems and ways for solution, planning of activities, information exchange and coordination. Political commitment increased due to this project, as the local government recognized the public health impact of (MDR)$\mathrm{TB}$ and insufficient control. As a result the financial contribution in social support of MDR-TB patients at EKO increased dramatically; from 617,000 Kazakhstan tenge (KZT) $(4,410$ USD) in 2008 to $18,379,500 \mathrm{KZT}(123,350$ USD) in 2011. Currently, the working group continues its work, without the project team's support.

The effectiveness of psycho-social support stimulated the local government to decide on inclusion of psychologists and social workers in staff lists of TB services. Since February 2011 social workers and psychologists are available for all TB patients in these two cities, and the local government is planning to appoint coordinators for social support for TB patients at the oblast level, and in each rayon. Additionally due to an order of the Ministry of health issued at the beginning of 2012, social workers and psychologists currently are available for patients in primary health care facilities.

\section{Psychosocial Support Groups}

In 2010, 426 MDR-TB patients started second-line drug treatment in EKO. Mostly patients in the continuation phase, on an outpatient basis, were enrolled for psycho-social support as the risk of treatment interruption and default is highest then. In total, 228 received support in the period March-December 2010. Most (77\%) patients lived in the two cities where the PSSGs were based; the others were from rural settings. Table 1 shows the characteristics of the patients enrolled. The majority of patients were male $(61 \%)$ and unemployed $(80 \%)$ at the time of the interview. It is not clear how many patients were unemployed due to TB disease.

Out of the total of 228 patients who needed support, 177 (78\%) were considered to be in need of psychological support by the PSSG of whom 157 (89\%) were provided with this support, and $213(93 \%)$ were deemed to need social support of whom $175(82 \%)$ received it. The main reasons why some of the patients who needed support but did not receive it were that the two patient support groups could not cover all patients, especially those living in remote areas, and that some of the problems encountered by patients could not be solved by the PSS group, like improving general living conditions.

Psycho-social support was based on the individual patient needs. Therefore, MDR-TB patients enrolled in the program received different types of support: food and hygiene parcels, assistance in any kinds of documentation, assistance in preparation of dossier and submission to get state allowance, interim housing, and admission of children in kindergarten free of charge and also in occupation (Table 2). Many home visits were made; 195 were related to clinical care, 119 to assessment of social status, and 63 to psychological counseling of patients and relatives.

The project encouraged the prison system to also actively involve a prison psychologist in patient counseling on TB treatment adherence. A psycho-social support program was also started in the prison TB hospital in EKO and psychological support was provided to sixty five TB patients by prison psychologists trained in interpersonal communication. Social support was provided by prison system itself (mainly related to documentation) and distribution of small food and hygiene parcels provided by the Global Fund.

\section{Evaluation of Psycho-Social Support}

One hundred ninety MDR-TB patients enrolled in the PSS program were interviewed to find out their opinion about the program and provided support. Among them, 179 (94\%) were (very) satisfied with the psycho-social support provided.

The patients were asked about factors they considered as important in order to get cured from MDR-TB. Factors mentioned as important were most often (81\%) medically related (timely diagnosis of MDR-TB, access to free of charge treatment, quality of treatment, supervision by medical workers), or related to social support (69\%). Fifty percent mentioned psychological support. Eighty nine percent of MDR-TB patients responded that PSS support increased their adherence to treatment and helped them to solve some individual problems.

Before the start of the PSS program, 44 (23\%) out of the 190 respondents had interrupted treatment at least once. One of the most common reasons for stopping treatment was the need to earn money. After inclusion in the PSS program, only one $(0.5 \%)$ MDR-TB patient had interrupted treatment once, due to alcohol addiction. The technical assistance on PMDT including the PSS program also had a positive impact on adherence to treatment among those MDR-TB patients who were not included in the PSS program: adherence to treatment at continuation phase among all MDR-TB patients in whole oblast has gone up from $48 \%$ to $97 \%$.

\section{DISCUSSION}

TB is predominately a disease of socially vulnerable groups, making adherence to the extended course of treatment a considerable challenge. Ensuring adherence to TB treatment is a major programmatic challenge for many countries. Without effective strategies to assure patient

Table 1. Characteristics of Multi-Drug Resistant Tuberculosis Patients Enrolled in the Psycho-Social Support (PSS) Program in East Kazakhstan Oblast, Kazakhstan, March-December 2010

\begin{tabular}{|c|c|c|c|c|c|c|}
\hline \multirow{2}{*}{$\begin{array}{c}\text { Number of MDR-TB Patients Enrolled on PSS } \\
\text { Program }\end{array}$} & \multicolumn{2}{|c|}{ Gender } & \multirow[t]{2}{*}{ Unemployed } & \multirow[t]{2}{*}{ Homeless } & \multirow[t]{2}{*}{ Prison History } & \multirow[t]{2}{*}{ Alcohol and/or Drug Use } \\
\hline & Males & Females & & & & \\
\hline 228 & $139(61 \%)$ & $89(39 \%)$ & $183(80 \%)$ & $3(1 \%)$ & $20(8 \%)$ & $24(10 \%)$ \\
\hline
\end{tabular}


Table 2. Characteristics of Psychological and Social Support Provision for 228 MDR-TB Beneficiaries Enrolled on the PsychoSocial Support (PSS) Program in East Kazakhstan Oblast, Kazakhstan, March-December 2010

\begin{tabular}{|c|c|c|c|c|c|c|}
\hline $\begin{array}{c}\text { Psychological } \\
\text { Support }\end{array}$ & $\begin{array}{c}\text { Food and Hygiene Parcels } \\
\text { at Monthly Basis }\end{array}$ & Documentation & $\begin{array}{c}\text { Disability } \\
\text { Allowance }\end{array}$ & $\begin{array}{c}\text { Free of Charge Access } \\
\text { to Kindergarten }\end{array}$ & $\begin{array}{c}\text { Temporary } \\
\text { Housing }\end{array}$ & $\begin{array}{c}\text { Assistance to Find } \\
\text { Employment }\end{array}$ \\
\hline \hline $157(69 \%)$ & $85(37 \%)$ & $21(9 \%)$ & $48(21 \%)$ & $7(3 \%)$ & $3(1 \%)$ & $6(3 \%)$ \\
\hline
\end{tabular}

adherence and appropriate patient management, the danger that drug resistant forms of TB will develop increases [1, 79].

The patients enrolled in the psycho-social support program in East Kazakhstan region suffered from a myriad of social and psychological problems including alcoholism, unemployment, very low-income, absence of social support, homelessness, and lack of official documentation that prevented access to state social support [10]. Understanding problems that patients face during TB treatment and patients perceptions may help the Kazakhstan TB control program to make appropriate efforts to solve or alleviate these problems.

Our finding that financial difficulties are a major reason for default has been observed before $[11,12]$. Therefore social support seems to be important for many MDR-TB patients in Kazakhstan. Also, further expanding outpatient TB treatment and care might make treatment more comfortable and acceptable for patients. Psychological support should be also an essential element of programs supporting treatment adherence; $69 \%$ of our beneficiaries welcomed psychological counseling and pointed that it was very important for them.

The psychosocial support program is a targeted patientcentered program to intensify treatment support and accompaniment that. The program in East Kazakhstan very successfully helped MDR-TB patients at high risk of treatment default enrolled for patient support programamong MDR-TB patients supported by psychosocial support program there were no defaulters.

Importantly, the project activities contributed to overall MDR-TB management and adherence to treatment during the ambulatory phase of treatment, also for those patients not enrolled in the PSS program. As a result DOT for all MDRTB patients in the region significantly improved - from $48 \%$ to $97 \%$ of doses. Division of intake of second-line drugs divided into different portions over the day decreased from $20 \%$ in 2009 to $0 \%$. Interruptions of anti-TB drug intake for at least a day decreased from $18 \%$ to $4 \%$ among all MDRTB patients in whole oblast.

The PSS program also showed that individual work with patient education needs to be focused not only on clinical aspects but also more general on their rights and obligations. Before the PSS program only $15 \%$ of patients knew about the opportunity to apply for state social support - they did not know about their right to apply and did not know how to do it. During the project intervention, members of PSSGs improved this by communicating relevant and useful information to patients and also by educating patients on how to do this, if necessary in the future.

The existing possibilities for TB patient support vary greatly within the country and depend on the available service providers, commitment of local authorities, and socio-economic status of the region. The East Kazakhstan oblast experience contains successful examples of interventions targeting TB patients implemented jointly by governmental and non-governmental organizations, as represented by KNCV. Before the PSS program was implemented in East Kazakhstan oblast, selection criteria for TB patients eligible for social support were not transparent and not many patients actually received support. Successful results of piloting psycho-social support in East Kazakhstan region stimulated local partners to expand the program in 2011 to all TB patients.

\section{RECOMMENDATIONS}

To make the support program efficient and effective, it is important to develop a legal basis for provision of direct support to patients and therefore increase state resources, create an institutional framework with links between TB facilities and other organizations providing care and support to TB patients $[2,6]$.

Fostering the non-governmental organizations (NGO) and other community based organizations involvement in psycho-social support for TB patients also should be an essential element of National TB policy [14,15] because without political commitment and clear support from national level it would be difficult to change overall situation in the country. It means that the national TB program and government should consider NGOs and the community as co-players in TB control.

There is a need to develop standard methodologies and performance based mechanisms for psycho-social support for all TB patients in Kazakhstan with a clear description of objectives of and guidelines for implementation of PSS, including on what is the minimum support to be provided and on which patients are eligible for PSS. In addition, a monitoring and evaluation (M\&E) tool on how to monitor and report performance should be developed. In the monitoring process the national TB programs should play a central role by introducing monitoring indicators related to PSS in national M\&E plans.

Collaboration between TB services and social organizations and substance abuse services, as well as availability of psychological counseling for patients are support modalities for improving adherence to treatment. Networks for patients involving TB medical staff, social services, psychologists, family members and friends, should be developed and institutionalized at country level to enable successful treatment.

\section{CONCLUSION}

Our experience showed that successful treatment of patients requires a programmatic and patient-centered approaches, strong commitment and innovations. 
A multidisciplinary approach in patient support, including psychological and medical counseling, DOT support, social and legal advice, and other social support like food packages are not yet available for all TB patients in Kazakhstan. Usually such an approach is provided only within projects implemented by international organizations [11-13]. Following the positive results shown by our pilot project, the government of East Kazakhstan oblast has adopted the approach for implementation in the whole oblast. We now advocate for expansion of the PSS model to the rest of the country.

\section{CONFLICT OF INTEREST}

The authors confirm that this article content has no conflict of interest.

\section{ACKNOWLEDGEMENTS}

The project was made possible by the generous support of the American people through The Global Health Bureau, Office of Health, Infectious Disease and Nutrition (HIDN), United States Agency for International Development (USAID), and is supported financially through the TB Control Assistance Program (TB CAP) under the terms of Agreement No. GHS-A-00-05-00019-00. The content of this article is the responsibility of the authors and does not necessarily reflect the views of USAID or the US government. The authors would like to acknowledge help in data collection by KNCV colleague A. Tursynbayeva, and the following specialists of East Kazakhstan oblast TB program: A. Asylbekova, and I. Khmelnitskaya.

\section{REFERENCES}

[1] Guidelines for programmatic management of drug-resistant tuberculosis. Geneva: World Health Organization 2007.

[2] Jakubowiak WM, Bogorodskaya EM, Borisov SE, Danilova ID, Kourbatova EV. Risk factors associated with default among new pulmonary TB patients and social support in six Russian regions. Int J Tuberc Lung Dis 2007; 11: 46-53.

[3] Gelmanova IY, Taran DV, Mishustin SP, Golubkov AA, Solovyova AV, Keshavjee S. 'Sputnik': a programmatic approach to improve tuberculosis treatment adherence and outcome among defaulters. Int J Tuberc Lung Dis 2011; 15: 1373-9.

[4] Miller AC, Gelmanova IY, Keshavjee S, et al. Alcohol use and the management of multidrug-resistant tuberculosis in Tomsk, Russian Federation. Int J Tuberc Lung Dis 2012; 16: 891-6.

[5] Vega P, Sweetland A, Acha J, et al. Psychiatric issues in the management of patients with multidrug-resistant tuberculosis. Int $\mathrm{J}$ Tuberc Lung Dis 2004; 8: 749-59.

[6] Jakubowiak W. Social support for patients: evidence from experience of a Russian Federation. Int J Tuberc Lung Dis 2004; 8 (Suppl 1): S12.

[7] Cox H S, Kalon S, Allamuratova S, et al. Multidrug resistant tuberculosis treatment outcomes I Karakalpakstan, Uzbekistan: treatment complexity and XDR-TB among treatment failures. PLoS ONE 2007; 2: e1126.

[8] Charles PF. Social support services for tuberculosis clients. NewYork: National Tuberculosis Center 1999.

[9] Misra H, Hansen EN, Sabroe S, Kafle KK. Socio-economic status and adherence to tuberculosis treatment: a case - control study in a district of Nepal. Int J Tuberc Lung Dis 2005; 9: 1134-9.

[10] Frieden TR. Tuberculosis control: critical lessons learnt. Indian J Med Res 2005; 121: 140-2.

[11] Fry RS, Khoshnood K, Vdovichenko E. Barriers to completion of tuberculosis treatment among prisoners and former prisoners in St. Petersburg, Russia. Int J Tuberc Lung Dis 2005; 9: 1027-33.

[12] Dodor EA, Afenyady GY. Factors associated with tuberculosis treatment default and completion at the Effia- Nkwanta egional Hospital in Ghana. Trans R Soc Trop Med Hyg 2005; 99: 827-32.

[13] Jakubowiak WM, Bogorodskaya EM, Borisov SE, Danilova ID, Lomakina OB, Kurbatova EV. Social support and incentives programme for patients with tuberculosis: experience form Russian Federation, Russia. Int J Tuberc Lung Dis 2007; 11: 1210-5.

[14] WHO. Implementing the WHO Stop TB Strategy: a handbook for national tuberculosis control programmes. Geneva: WHO 2008.

[15] WHO. The role of civil society organizations in the Stop TB Partnership: opportunities for engagement. Consultation meeting to strengthen the active engagement of civil society organizations in the TB area of work of the WHO. Geneva: WHO 2010. 